\title{
A construction of bullying in a primary school in an underprivileged community: an ecological case study
}

\author{
Victoria Margaret Timm \\ Department of Psychology, University of Pretoria, South Africa \\ vicky.timm@up.ac.za
}

\section{Linda Marie Eskell-Blokland \\ Department of Psychology, University of Pretoria}

This article is based on a master's dissertation completed through the University of Pretoria. Conversations around behavioural problems in three primary schools in Mamelodi, an underprivileged community in South Africa, explored contextually relevant ideas, in the form of discourse, focusing on the experience of bullying from the perspective of the participants (children identified by the school as engaging in bullying behaviour, school staff, and the children's families). Semi-structured interviews were conducted with the principals (school gatekeepers), and with other participants identified by each other during the interview process. Two figures prominent in the media on the topic at the time of this study were also included to provide discourses on bullying from wider society. An ecological approach within a post-modern social constructionist theoretical framework was used. In this article one ecological case study from one of the three schools was used to explore the aims. Discourse analysis was used in the construction of the various discourses emerging from the conversations. The participants' ideas around bullying are described, focusing on the discourse themes of "community and bullying", "profile of teachers in the community", "bad child, good child", "undefined problems" and "family discord". The aim of this article is to provide an ecological description of bullying, through discourse, in the context of this case study by exploring the participants' ideas on and experience of bullying in a primary school situated in the township of Mamelodi. Implications for intervention are considered.

Keywords: bullying; case study; discourse analysis; ecological; schools; South Africa; violence

Wolhuter and Steyn's (2003) research shows that poor learner discipline is an acute problem in South Africa. Similarly, Pienaar (2003) says that discipline has collapsed in many South African schools. The local literature (Wolhuter \& Steyn, 2003; Smit, 2003) highlights a need for research on behaviour problems such as bullying in South African schools, particularly in underprivileged areas, because schools in such areas have not previously been explored by means of extensive research. This article therefore explores contextually relevant ideas, through the discourses of the participants, in an ecological case study of bullying in a primary school in the township of Mamelodi, Pretoria.

Against a background of large-scale social transformation, South African psychologists are working towards building a relevant profession for local contexts (Bakker, 1999). Bakker (1999) and Eskell-Blokland (2005) emphasise a need to use an approach that focuses on the meanings around the problem, as experienced by those who are directly involved. Eskell-Blokland (2005) suggests that conversations within a local township context, for example, may be a more useful guide to practice than university texts that contain only mainstream psychological theories. Polkinghorne (1992) points to studies that show that psychotherapists rarely find research that is relevant to practice, as practice is ever-changing and context-bound. Hence, this article attempts to contribute to a body of research necessary to build a locally relevant profession. In keeping with the aims and approach of this article, the emphasis is on the participants' ideas on bullying in the context of the study.

For the purposes of this article, the term "ecology" as a psychological concept is loosely described as the relationships that interlink people around a problem (Cole, 1991). In keeping with the ecological approach (Cole, 1991), the participants themselves in dialogue with each other and myself, during the research process, constructed the problem system - those interlinked around the problem of bullying. During the interviews, the following ecological elements were interlinked around bul- 
lying: the children's and schools' communities, the teachers at the schools concerned, the children identified as exhibiting bullying behaviour and their families. The ecological case study discussed in this article therefore consists of ten participants from these various ecological elements.

Neser et al. (2004) define bullying as behaviour consisting of repeated and intentionally hurtful acts, using words or other kinds of behaviour perpetrated by children (those who bully) against other children (those who are bullied). In this article, this definition is used to define bullying behaviour. With regard to the eleven-year-old child from the case study discussed in this article, the bullying behaviour was constructed as continual fighting, involving physical abuse of usually younger children. The acts of physical abuse were continual, over a period of at least twelve months, and they occurred across different contexts. His behaviour remained unaffected by most measures of discipline directed at changing this behaviour. This is in keeping with the above definition of bullying.

The concept of knowledge in this article is understood within a social constructionist framework. Language is the vehicle through which reality is constructed. Knowledge becomes narrative, embodied in stories communicated through language. Knowledge is seen as a conversation between two or more people about a topic that is of interest (Kvale, 1996). In this article, that topic is bullying. The construction of knowledge and understanding of our world is therefore a social process rooted in language (Burr, 1995; Gergen, 1985; Steier, 1991).

Discourse is defined as broad patterns of talk or systems of statements operating within these conversations (Terre Blanche, Durrheim, \& Kelly, 2006, p. 328).

\section{Discourses around bullying}

Maree (2005) claims that bullying is prevalent throughout South African society, in the family, tertiary institutions and the workplace, as well as schools. With reference to different research across South Africa using samples of high school learners, Townsend, Fisher, Chikobvu, Lombard, and King (2008) report the percentages of children involved in bullying as follows: Cape Town and Durban high schools (36.3\%), rural schools in Mpumalanga (11.8\%) and high schools in Tshwane (61\%). A national study reported that $41 \%$ of high school learners are involved in bullying incidents (Townsend et al., 2008). No statistics were found for South African primary schools.

Behaviour problems, such as bullying in schools, have been associated with the following: poverty, performing poorly in school, a lack of social skills, hopelessness with regard to attaining employment (Noddings, 1996), the influence of movies and other media (Derksen \& Strasburger, 1996; Maree, 2005; Noddings, 1996), certain kinds of parenting, lack of parental supervision at home, gang membership or peer pressure (Derksen \& Strasburger, 1996; Futrell, 1996), involvement with drugs and alcohol (Futrell, 1996; Stewart, 2004), child abuse and family violence (Haugaard \& Feerick, 1996), and a decline in the morals of society in general (Noddings, 1996).

The after-effects of bullying can be severe, possibly lasting into adult life and sometimes never fully dissipating (Maree, 2005). According to Townsend et al. (2008), research shows the following consequences of bullying: psychosomatic complaints, depression and anxiety, and suicide. Those perpetuating bullying were likely to have one or more criminal convictions when reaching adulthood and to have diagnosable psychiatric disorders. Two thirds of school shooters in the USA reported having been the victims of bullying (Townsend et al., 2008).

\section{Aim and objectives}

The aim of this article is - through the use of an ecological case study - to contribute to an ecological description or construction of bullying in primary schools situated in the Mamelodi Township. To meet this aim, two objectives are pursued. The first is to provide a description or construction of the participants' own perspectives and meanings around bullying and any possible solutions that they may offer. The second is to contribute to a relevant body of research necessary to build a locally relevant profession, one in which the interface between the individuals, the school community and the wider community are considered from the perspective of those involved. 


\section{Ecological thoughts on bullying}

Ecological thought facilitates seeing the world as a dynamic set of interchanging networks and elements. Child deviance can be viewed as an element in these networks reflecting the values of a human ecology in which it is embedded. However, as an open ecology it is subject to change (Rhodes \& Tracy, 1974a, cited in Rhodes, 1996).

South Africa has been undergoing intense social change, on political as well as socio-cultural levels. These changes can induce significant psychological effects (Eskell-Blokland, 2005) and thus add to the dynamics of the context of this particular study. Change may affect traditional structures and meanings (Hickson \& Kriegler, 1991) leaving young people without clear guidelines, which may lead to high-risk behaviour.

It may perhaps be argued that South Africa is suffering from similar problems as those found in the United States, which Aponte (1990) sees as a society that is losing the cohesiveness of family and community life. He attributes social problems in general to a breakdown of the values and structure of communities and American society as a whole. Aponte (1990) claims that the poor are dependent on social structures for their survival and well-being. Such structures are typically provided through national policies. A breakdown in these structures leaves especially the poor, who often have few alternative resources, struggling in crippling social conditions. He also highlights the lack of reliance on therapeutic approaches that incorporate dealings with community institutions into the conceptual frameworks and interventions of ongoing therapy in community contexts (Aponte, 1990). This reflects a need for the worlds of research and practice to be brought together (Brion-Meisels \& Selman, 1996) and a need to provide knowledge that will promote the incorporation of community institutions into intervention programmes.

Aponte (1990) claims that, to facilitate understanding, any therapeutic model that integrates the community into its treatment approach must incorporate contextual factors in the assessment process. In such an approach, research methodologies and therapeutic programmes used must include working with families, schools and communities (Futrell, 1996).

More importantly for the purposes of the current study, Gilligan (1982, cited in Brion-Meisels \& Selman, 1996) claims that we must listen carefully for, and give power to, the diverse voices that make up the entire school community when working in such contexts. In keeping with this approach the voices of ten participants from different ecological levels were included in the ecological case study described, as were discourses around the wider community issues and context perceived by the participants as impacting bullying behaviour.

Maree (2005), writing specifically on bullying in South African schools, regards the current school situation as part of the broader picture of spiralling levels of violence and crime which dominate South African society. Examples of this violence include rising teenage suicide rates, bullying and other forms of abuse. In the historically under-resourced and neglected communities of South Africa, violence or other forms of aggression may have become entrenched as one way of dealing with problems ranging from family issues to community or political disputes (Maree, 2005).

Aboud and Miller (2007) indicate that interventions that target victims and bullies alone have met with limited success. Reference to interventions like this motivated the current study to look at the problem of bullying through a theoretically wider perspective, in this case, an ecological approach.

\section{METHODOLOGY}

\section{Descriptions of the research setting: Mamelodi}

South African townships have developed their own culture, a mixture of traditional and urban ways of life (Eskell-Blokland, 2005). Typically, the residents come from different language groups (Heller, Price, Reinharz, Riger, \& Wandersman, 1984). In Mamelodi, as in many other South African townships, living conditions are diverse, ranging from well-built brick houses to small informal dwellings 
made out of sheet metal. The context of this study is underdeveloped and underprivileged in that the inhabitants are mostly from a low socio-economic strata and the area is under-resourced (EskellBlokland, 2005).

\section{Theoretical approach}

An ecological approach within a postmodern, social constructionist theoretical perspective was chosen for this study, as it recognises multiple points of view and multiple realities, all of which are seen as equally valid (Burr, 1995), although, in social interaction, some viewpoints are given more credence than others (Shotter, 1993). The ecological approach emphasises context; the social constructionist influence emphasises the importance of language: what is experienced as reality is constructed through relational conversations. Everyday conversations are influenced by the wider conversations that we experience in society and in our culture (Shotter, 1993). The ecological influence emphasises the importance of relationship between the many people who are involved in a situation, problem or constructed reality, through their conversations with or about each other in relation to it. Gergen (1985) states that social constructionism places knowledge within the process of social interaction. Ecology, in this article, moves away from the study of roles and structure, and the relations between them to an ecology of ideas, which are constructed through social interaction and expressed in language (Anderson \& Goolishian, 1986). Through social interaction during the interviews between the researcher and the participants, the ideas on bullying were co-constructed and presented in the results section of this article.

Shotter (1993) emphasises that everyday interaction and conversational exchange is influenced by socio-historical and socio-cultural background discourses, constructing our views of reality and the ways in which we talk about it (Shotter, 1993). According to Gergen (1985), all knowledge, including psychological knowledge, is socially specific, influenced by the historical and cultural discourse. Therefore these realms should be introduced into research if we are to understand psychological and social life (Burr, 1995). The results section of this article includes the wider discourses of community and context as they were seen in relation to bullying.

\section{Research design}

Three schools participated in the original master's dissertation on which this article is based. Due to the length limitations of this article, this report focuses on the analysis of one detailed ecological case study.

The ecological case study focused on ten participants. The principal, seen as the school's gatekeeper by the researcher, was approached first. He referred the researcher to the life orientation coordinator, who identified the child (called "Kgosana" in the study for the sake of confidentiality) as engaging in bullying behaviour. After the initial contact with the principal, the rest of the members of the ecology (the life orientation teacher, the child's mother, aunt, favourite teacher, class teacher and grandmother) identified each other by indicating, during the interviews, which people they felt they would like to include in conversations around Kgosana's bullying behaviour. In this way the ecology was constructed by the participants, in keeping with the theoretical approach of the study. The two members of the wider community included in this study were chosen by the researcher because they were prominent in the media on the topic of bullying at the time when the study was done. They worked in many different schools and drew from their extensive experience either in teaching and/or working with bullying and its effects in schools. They provided some background conversations around bullying that could influence the smaller ecology of this particular school and case study. One of these participants is a manager of a centre concerned with community violence and the other the director of a teachers' union. The ecological case described was influenced by many more interacting discourses that lie beyond of the scope of this article.

One or two semi-structured interviews lasting approximately fifty minutes were held with each 
participant. A few general questions around the participants' experience of bullying were asked. Interviews enabled the participants to be questioned on the same issues and allowed flexibility to probe the topic further when necessary (Potter \& Wetherell, 1987). The interviews were audio-taped with the consent of the participants and then transcribed. Discourse analysis was used in the analysis of the conversations in the interviews.

Discourse analysis uses language as its unit of analysis in keeping with the social constructionist approach and aims of this study. This approach analyses the participants' language or conversations and the meanings, experiences and ideas found within them. Drawing on Shotter's (1993) notion of "the process of the movement of chaos to order at work" (p. 179), the themes of discourses presented here were constructed by using the "tricks" described by Terre Blanche et al. (2006, p.331) and the conceptual tools described by Shotter (1993, p.179), as well as techniques from Potter and Wetherell (1987). Amongst other methods, the analysis looked at metaphors, terms, phrases and patterns of language use, the presentation of different sides of argumentation or binary oppositions, justification, utterance and flow. The methods that we use to organise our work influences what we see. These methods present reality as ever-changing and constructed (Freedman \& Combs, 1996). The analysis must be read with this in mind. Due to the limitations of this article, the detailed analysis is not presented, only some of the abridged themes of the emerging discourses substantiated by some examples of direct quotes from the participants are included in the results section (these are italicised to highlight the voices of the participants). Descriptions of the world in language invite certain kinds of action; thus, constructed knowledge and social action occur together (Burr, 1995). The possible actions that the discourses can result in (Shotter, 1993) are included in the form of preliminary suggestions for the construction of an ecological intervention.

The societal and contextual discourses that emerged in the conversations with the two members of the wider community can influence the discourses in the small environment of the school. Both the principal's and the life orientation co-ordinator's discourses centre on bullying in the small environment of the school. Kgosana's family members and personal teachers' discourses centre on his bullying behaviour, particularly in the classroom and at home. Each of the discourses on the different levels of the ecology presented here influence one another. This article presents some of the themes of discourse emerging through the discourse analysis and the implications of these for therapeutic intervention.

\section{Ethics}

Permission for the original, broader study was obtained from the Ethics Committee at the University of Pretoria, the Department of Education, and the three schools participating in this study. Informed consent was obtained from the participants. Written permission was obtained from the children's guardians for them to participate and assent was obtained from the children. Pseudonyms were used to protect the identity of the participants and identifying information was altered. Withdrawal from the study was accepted at any point in the study. All the children and their families participating in the study were offered and engaged in counselling around the bullying behaviour of the children.

\section{RESEARCH RESULTS AND DISCUSSION}

Within the above theoretical framework and the use of discourse analysis (Potter \& W etherell, 1987; Shotter, 1993; Terre Blanche et al., 2006), the following themes of discourses emerged from the conversations between the researcher and the participants. The themes are presented as co-constructed knowledge of an ecology of ideas around bullying, which are constructed through social interaction and expressed in language. This interaction and conversational exchange between the researcher and participants is influenced by socio-historical and socio-cultural background discourses (Shotter, 1993). Some of these wider societal and contextual discourses are presented as they were seen in relation to bullying. Descriptions of the world in language invite certain kinds of action and behaviour 
thus constructed knowledge and social action occur together (Burr, 1995). Following this concept possible actions that the discourses can result in are included in the form of preliminary suggestions for the construction of an ecological intervention (Shotter, 1993).

\section{Discourses around community and bullying (background voices to bullying)}

The director of the teachers' union (hereafter referred to as "the director") and the manager of the centre concerned with community violence (hereafter referred to as "the centre manager") both position schools within a wider community. This discourse was constructed by the director's phrase: "[These] community based schools" and the centre manager's comment that "schools don't exist in isolation. Schools are part of communities".

The centre manager places the schools in the wider context of the violent "South African society" and the "messages of violence" sent by society. The centre manager illustrates this interactive spiral between incidents of bullying and the wider community through the following example:

There is a school in A... There were, I think, two boys... fighting another [boy] and the father of the other [boy] went to the school and stabbed the two boys with a knife ... there was a plan that there would be a revenge attack [by] the communities - it [the violence] was spreading into communities and the police came with vicious dogs... yes, there is a problem - but the response to the problem [of violence and bullying] ... is invalid.

The wider discourse of societal violence also enters the local school ecology through the homes from which some of these children come. This is constructed in the conversation with the principal describing the predicament of a child from the informal settlement by the phrase "sjambok[s] the little one into silence... [that's] the provision that mom can do". The possibility of exposure to the discourse of violence runs through all strata of society, bringing it into the local school ecology: "I don't know as to whether my little ones also that are here don't go through the very same" (the principal). The teachers are also constructed by the centre manager as part of these wider discourses, of violence experiencing and perpetuating them: “... they are part of the community, they are part of S.A., they also believe in violence... I don't think some of them do it intentionally but they are a product of this country".

In the family ecology, the message of violence was also heard in what Kgosana's grandmother said: "... the man [Kgosana's neighbour] says he's going to kill them [Kgosana and his friends]." Children who bully hear this violent discourse, experiencing it first-hand and hearing its message: "[Violent] messages get to families, get to communities ... [they are] part of everyday life" (the centre manager).

Implications for intervention: actions that the discourses can result in

Any intervention programme for bullying should address, or at least acknowledge, these wider societal discourses that children who bully are exposed to. Given the strength of the discourse of violence in South Africa, it seems that strategies to counter bullying need to be directed at all the levels of the ecology where the message of violence is heard. Many family therapy authors acknowledge the impact of background voices in the form of "larger systems" (Landau-Stanton, 1982, cited in Le Roux, 1992, p. 43). Le Roux (1992) claims that attempts to transform and engage these societal and community background voices or "larger systems" (p.43) in treatment programmes require seeing voices as comprising individuals, as people work with specific individuals rather than large systems (Le Roux, 1992).

The strategy of intervention to construct an alternative voice to violence has to match the strength of this (already structured) discourse in our society (Timm, 2007). The conversations with the centre manager emphasised the need for a wide intervention programme or "strategies", "by the government, by all institutions". The centre manager said: "The only way to sustain it [work in the small environment of the schools with bullying] is for us to push the government to come up with 
policies to integrate this kind of work in the schools." If the interventions are made part of the policy and wider interventions, they will become part of the structured discourses or dominant narratives (Freedman \& Combs, 1996) of society. The effect of not integrating interventions with government policy is constructed, for example, through this phrase: “... otherwise we must keep on doing this work [with bullying] forever and we will not see much" (the centre manager). Research in this area can help to focus the government's attention on the necessity of developing policies to address violence and bullying intervention in schools. Research could explore what effective "strategies" actually consist of.

\section{Profile of the teachers in the community}

The conversations with the director of the teachers' union constructed the disciplinary problems in schools, including bullying, as related to educators' loss of status:

... the profile of educators has dropped tremendously... [people] don't deem educators that worthy any more, ... Teachers are still central to schooling and teaching,... we need to re-establish that... When teachers bring problems to the attention of parents... it should be dealt with...very, very clearly, and the... input from both parties...should be taken into account. There's ... a disregard, generally..., of the educators.

Disciplinary problems such as bullying are related to the disengagement of parents as members of the school ecology. "It's very difficult to make contact with parents sometimes. It's ... hard to ... deal with the [bullying] problems immediately and effectively" (the director). Parents are called in to discuss the situation with discipline problems but they rarely come. Thus teachers have no support from parents in attempting to discipline children who bully. This discourse was noted across conversations with the principal, the support learning co-ordinator, and the centre manager (Timm, 2007).

\section{Suggestions for intervention: actions that the discourses can result in}

A discourse of "communication as a solution" (Timm, 2007) is constructed by the principal as a way of remedying this situation: "If some of our parents could just take that when we say...come, let's talk". The director constructed communication or co-operation between parents and teachers as a solution: "The input from both parties... should be taken into account." The phrase "input from both parties" especially constructs this discourse as a further way of bringing about interaction between parents and teachers, thereby engaging parents in solving disciplinary and bullying problems. The principal is trying to establish an "assist programme" to achieve such interaction: "We have started a teacher-parent assistance programme, ... Because we notice if we are ...going to do things... ourselves... we might not succeed...we still have a problem with parents. That's why we're forming this body in the school."

Based on the discourse of "communication as solution," structures such as the parent-teacher assist programme envisaged by this principal could be implemented in schools. Stanton and Landau-Stanton (1988, cited in Le Roux, 1991, p. 44) claim that "expansive" approaches such as these can prevent therapeutic stagnation. Arranging network sessions can be a collaborative way of using the resources of the ecology. A programme that facilitates communication and relationship between parents and teachers based on a re-framed discourse may be helpful. The programme could be based on communicating around problems that do not belong to specific parents and their children and this may engage parents more easily. In other words, the discourse the principal suggests ("let's talk to you about your child's problem") can be reframed to construct the child's behaviour as belonging to the system as opposed to belonging to an individual child. For example: What are we going to do about this widespread problem in our school? If these programmes are framed as collaborative networks, focusing on the strengths of all involved, they could help to facilitate change (Stanton \& Landau-Stanton, 1998, cited in Le Roux, 1991). 


\section{Bad child, good child discourse}

Moving from the broader discourses that affect the school and hence the individuals in it, one can look at the specific discourses across the ecology that construct a bully as being a good, bad or naughty child. Five members of the ecology surrounding the problem story of Kgosana's bullying have direct contact with him. The discourse of the "bad Kgosana" initiated the conversations with Kgosana's mother, grandmother, class teacher and aunt. "... Kgosana is violent or angry ..." "Last year, he was naughty because he steals". "He's very bully[ing] and sometimes not co-operative." This negative discourse seems stuck and repetitive: most members of the ecology return to it continuously, describing Kgosana through this discourse (his mother, grandmother and class teacher). Only Kgosana's favourite teacher initiated the conversation with a positive discourse around him. "He is a wonderful boy ..." (Timm, 2007).

The discourse of the "good Kgosana" was constructed in response to questions on Kgosana's strengths or good points. Only Kgosana's aunt and favourite teacher found it easy to construct a positive discourse around him (Timm, 2007). These discourses are normalising: "As I have said and I am still saying... that is the behaviour of any other child... I won't take that as a behavioural problem" (Kgosana's favourite teacher). The other side of the argumentation, the discourse of the "bad Kgosana", is constructed by his aunt as perpetuating Kgosana's negative behaviour: "They should not remind him all the things he's done... if you do it to him he will continue doing all those bad things." The discourse of "bad Kgosana" itself perpetuates Kgosana's negative behaviour. It is a practical example of Shotter's (1993) notion of language inviting certain kinds of action and behaviour.

This discourse of the bad child could be maintaining the "stuck" patterns of Kgosana's behaviour, as constructed by his mother in the phrase, "he repeats doing it again and again" and his class teacher, who said: "But it [the change in behaviour] lasted for a week, ... he went back to the [bad] behaviour."

Implications for intervention: actions that the discourses can result in

Narrative therapy (Freedman \& Combs, 1996) can help individuals and families to construct alternative discourses for and with children like Kgosana. A form of narrative intervention could also be used in the school setting to encourage the system to construct these children differently, for example, by encouraging the strengths in the child, constructing an opportunity to develop alternative patterns of behaviour and accompanying alternative discourses to describe them. From the narrative perspective, identities are formed through stories (McAdams, 1985, cited in Howard, 1991). Human thinking is treated as story elaboration, which offers numerous implications for psychological theory, research and practice. The development of identity is seen as life story construction, and pathology is seen as a problematic life story (Rorty, 1979).

In the school ecology, the two teachers who manifested a pattern of positive discourse around children displaying behaviour such as bullying are the Life Orientation teachers (Kgosana's favourite teacher and the support learning co-ordinator). These teachers could be a natural resource within the school setting, both in their worldview and in the subject that they teach — one said: "You know what, because I am an L.O. teacher maybe that is why I can connect to them." If certain interventions were interwoven into the Life Orientation curriculum, it could be an effective way of sustaining ongoing intervention without overburdening other subject teachers.

\section{Bullying as an undefined problem and silence}

Description and ideas of the details around bullying and possible connections to what is happening in the environment, or in the interaction between members of this ecology around bullying behaviour, are missing in the initial interview conversations (Timm, 2007). When asked what they think about why Kgosana is bullying, they replied: “... but his naughtiness is, I don't know what kind it is ..." 
(Kgosana's mother). “... I don't know what to say about that ...” (Kgosana's class teacher). Kgosana himself does not construct details around what starts the fights: "Something happens." The subsequent interaction is also not detailed. Kgosana's aunt also did not initially construct any details around the situation, saying: "Why, I don't know?" These kinds of statements constructed a discourse of "the undefined problem" (Timm, 2007).

There is a "discourse of silence" around the problem of bullying that possibly interacts with the discourse of the undefined problem described above. Kgosana is silent around his problem, as is his mother, some of his teachers and significant male family members (Timm, 2007).

Kgosana's discourse of silence was constructed in the conversations with his mother, favourite teacher and class teacher: "He won't talk, he will tell you, 'Me, I don't have any problem'" (Kgosana's mother). The class teacher said: "[H]e didn't have any answer for me, look[ed] at me and kept quiet ... I don't know, 'cause he doesn't open up to me ..." The class teacher found it difficult to raise the issue when talking to Kgosana: "And, you know, it's hard for me to say ..." Kgosana's favourite teacher said: “... there is no time when Kgosana would tell me." Kgosana's grandfather and father did not participate in Kgosana's therapy or the research. Kgosana's father who is estranged from his mother lives in a different town to Kgosana. Kgosana's grandfather is reported by his mother and grandmother as having a strained relationship with the boy and refused to participate (Timm, 2007).

Despite the above discourses a solution offered to Kgosana by members of the ecology is that he be "open" about his behaviour. However, under the themes of discourses the "undefined problem" and "silence," there is no alternative "open" discourse, as no one in the ecology seems comfortable with or knows how to talk about the situation. Yet openness is still constructed as a solution: "If he will be open and tell you what is affecting him he will be fine" (Kgosana's mother). Kgosana's class teacher said: "I think if he can get a professional, who he can come and open up to him or her, who can state what his problems are." Kgosana's favourite teacher also constructs openness as a solution and a way of facilitating connection: "... that is why I can connect to them to that extent because when I start a lesson sometimes, not every time, I would ask them, 'how are you feeling today?' So they would tell me their feelings for the day." These conversations are still constructed as delegated to "spare time" in the education system. Even in Life Orientation lessons, the curriculum dictates that feelings are spoken about "sometimes, not every time".

\section{Implications for intervention: actions that the discourses can result in}

Initially there seems to be a lack of awareness of the process of interaction around bullying behaviour. However during the flow of conversation, discourse around the situation of bullying, meanings, understandings and feelings were constructed (Timm, 2007). "[They complain about Kgosana a lot], that's his problem" (Kgosana's mother); “... he just needs time, understanding, they need to understand him" (Kgosana's aunt). In keeping with the above suggestion from the participants to be open around the problem of bullying, psychotherapy could be used to construct a discourse around understanding this behaviour and the context in which it happens. Similarly, the Life Orientation curriculum could be used for conversations around the issues of bullying and feelings in general.

\section{Family discord}

A discourse of family conflict runs through the conversations across the family ecology reflecting a similar spiral of aggression as noted in the above example of bullying in the community given by the centre manager in the theme "discourses around community and bullying". This message of discord and aggression is present in family relationships too. There is discord between Kgosana and his grandparents - his mother commented: "... they [the grandparents] come out on top of [Kgosana]. They talk so many things. They talk so many things, that's his problem." His aunt said: "Ai, they [Kgosana and his grandparents] don't get along... not at all... When he was a child but right now they don't" (Timm, 2007). There is discord between Kgosana and his younger uncle - Kgosana, 
through an interpreter, said: “... the other uncle bothers him [Kgosana] and then he hits him, then the grandfather gets angry at [Kgosana]". Kgosana's mother and biological father clash; Kgosana's paternal grandmother and Kgosana's mother clash; and Kgosana and his paternal grandmother clash, as constructed in the conversations with his maternal grandmother: "No, [Kgosana] never stayed with [his father] because his mother was always fighting with [his father] until he leaves ...; the [paternal] grandmother doesn't like [Kgosana] and [Kgosana's] mother."

The conversation with Kgosana's maternal grandmother also revealed a discourse of distance between Kgosana's mother and his maternal grandmother and Kgosana and his grandmother: "I even go and fetch the mother and say your child is doing this and this ..." The phrases "the mother" or "Kgosana's mother" are often used by the grandmother to refer to her daughter. Only once during the conversation did she refer to her daughter as "my child". The grandmother consistently refers to all her other children as " $m y$ child". This seems to create distance between the grandmother and this daughter, Kgosana's mother. The binary opposition (Terre Blanche et al., 2006) to distance is constructed with the use of the word " $m y$ " which constructs relationship, a sense of belonging and attachment. The use of the words "the mother" and "your child" constructs the link between Kgosana and his mother, whilst distancing them both from the grandmother (Timm, 2007).

\section{Implications for treatment: actions that the discourses can result in}

The above theme of discourse echoes the ideas in literature cited earlier such as Derksen and Strasburger (1996) and Futrell (1996) that claim a relationship between family dynamics and bullying. Family therapy could be used to address discord in families.

\section{CONCLUSION}

The more voices that are heard in an ecology, the more the ecological approach widens perspectives on the situation surrounding behaviours such as bullying. The conversations with the manager of the centre concerned with community violence and with the director of the teachers' union brought about a wider perspective on intervention because of their wider involvement across different schools. The centre manager's strategies move from the small school environment to wider interventions, including many organisations and government policy. Given the strength of the discourse of violence in South Africa, it seems that strategies to counter bullying need to be directed at all the levels of the ecology where the message of violence is heard. "A co-ordinated effort" (the centre manager) would be a way of achieving such a multi-layered strategy. The co-ordinated inclusion of many voices would help to create community as a system of relationships by forming community therapeutic networks (Le Roux, 1992) and this approach would also develop and strengthen an alternative voice to the current voice of violence, aggression and bullying.

Intervention at wider levels does not preclude or negate interventions in the micro-environment or one-on-one interventions. Based on the conversations reported above within the ecology of bullying, school interventions, family interventions and one-on-one interventions could all be included when dealing with problems around bullying. According to Bakker and Snyders (1999), the diffuse theoretical framework of ecosystemic thinking should not detract from a local and individual emphasis. However, if this is the only level at which we intervene, while ignoring policy, we will succeed only in individual schools, with individual families and children (Timm, 2007).

It is hoped that the discourses emerging from this study can contribute to a basis for a contextrelevant intervention programme to address the extensive problem of bullying in this school and a similar process could then be carried out in other school settings.

\section{REFERENCES}

Aboud, F., \& Miller, L. (2007). Promoting peer intervention in name-calling. South African Journal of Psychology, 37, 803-819.

Anderson, H. D., \& Goolishian, H.A. (1986). Human systems as linguistic systems: Preliminary and 
evolving ideas about the implications for clinical theory. Family Process, 27, 371-393.

Aponte, H. J. (1990). "Too many bosses." An eco-structural intervention with a family and its community. Journal of Strategic and Systemic Therapies, 9, 49-63.

Bakker, T. M. (1999). A healer may yet emerge from behind the mask: Revisiting the tarnished image of psychology in Africa. Journal of Psychology in Africa, 9, 161-185.

Bakker, T. M., \& Snyders, F. J. A. (1999). The (hi)stories we live by: Power/knowledge and family therapy in Africa. Contemporary Family Therapy, 21, 133-154.

Brion-Meisels, S., \& Selman, R. L. (1996). From fight or flight to collaboration: A framework for understanding individual and institutional development in the school. In A. M. Hoffman (Ed.), Schools, violence and society (pp. 163-184). Westport, CO: Praeger.

Burr, V. (1995). An introduction to social constructionism. London, UK: Routledge.

Cole, R. E. (1991). Participant observer research: An activist's role. In W. F. Whyte (Ed.), Participatory action research (pp. 159-168). Thousand Oaks, CA: Sage.

Derksen, D. J., \& Strasburger, V. C. (1996). Media and television violence: Effects on violence, aggression and antisocial behaviours in children. In A. M. Hoffman (Ed.), Schools, violence and society (pp. 61-77). Westport, CO: Praeger.

Eskell-Blokland, L. M. (2005). Voice to the silent: An ecology of local knowledge in psychology. (Unpublished doctoral dissertation). University of Pretoria, Pretoria, South Africa.

Freedman, J., \& Combs, G. (1996). Narrative Therapy: The social construction of preferred realities. New York: Norton.

Futrell, M. H. (1996). Violence in the classroom: A teacher's perspective. In A. M. Hoffman (Ed.), Schools, violence and society (pp. 3-19). Westport, CO: Praeger.

Gergen, K. J., (1985). The constructionist movement in modern psychology. American Psychologist, 40, 299-275.

Haugaard, J. J., \& Feerick M. M. (1996). The influence of child abuse and family violence on violence in the schools. In A. M. Hoffman (Ed.), Schools, violence and society (pp. 79-97). Westport, CO: Praeger.

Heller, K., Price, R. H., Reinharz, S., Riger, \& Wandersman, A. (1984). Psychology and community change: Challenges of the future. Thousand Oaks, CA: Brooks/Cole.

Hickson, J., \& Kriegler, S. (1991). Childstock: The effects of apartheid on the mental health of South African children. International Journal of the Advancement of Counselling, 14, 141-154.

Howard, G. S. (1991). Cultural tales: A narrative approach to thinking, cross-cultural psychology and psychotherapy. American Psychologist, 46, 187-197.

Kvale, S. (1996). InterViews: An introduction to qualitative research interviewing. Thousand Oaks, CA: Sage.

Le Roux, P. (1992) Diversity and dialogue: The healing narrative. In J. Mason, J. Rubenstein, \& S. Shuda (Eds.), From diversity to healing. Papers from the Fifth Biennial International Conference of the South African Institute of Marital and Family Therapy (pp. 36-48). Durban, South Africa: South African Institute of Marital and Family Therapy.

Maree, K. (2005). Bending the neck to the yoke or getting up on one's hind legs: Getting to grips with bullying. Acta Criminologica, 18, 15-33.

Neser, J., Ovens, M., Van der Merwe, E., Morodi, R., Ladikos, A., \& Prinsloo, J. (2004). The victims of bullying. Acta Criminologica, 17, 28-47.

Noddings, N. (1996). Learning to care and to be cared for. In A.M. Hoffman (Ed.), Schools, violence and society (pp.185-198). Westport, CO: Praeger.

Pienaar, G. (2003). A different approach to classroom discipline problems. Educare, 32, 261-272.

Polkinghorne, D. E. (1992). Postmodern epistemology of practice. In S. Kvale (Ed.), Psychology and postmodernism (pp. 17-31). London, UK: Sage.

Potter, J., \& Wetherell, M. (1987). Discourse and social psychology: Beyond attitudes and behaviour. London, UK: Sage.

Rhodes, W. C. (1996). From my either/or to my both/and world. In L. Heshusius \& K. Ballard (Eds.), From positivism to interpretivism and beyond: Tales of transformation in education and social research (the mind body connection) (pp. 70-77). New York, NY: Teachers College Press.

Rorty, R. (1979). Philosophy and the mirror of nature. Princeton, NJ: Princeton University Press.

Shotter, J. (1993). Conversational realities. London, UK: Sage. 
Smit, M.E. (2003). The bully/victim problem in schools. Acta Criminologica, 16, 88.

Steier, F. (1991). Reflexivity and methodology: An ecological constructionism. In F. Steier (Ed.), Research and reflexivity (pp. 163-185). London: Sage.

Stewart, D. (2004). Learner discipline: An Australian perspective. Bulletin for Christian Fellowship, 69, 317-335.

Terre Blanche, M., Durrheim, K., \& Kelly, K. (2006). First steps in qualitative data analysis. In M. Terre Blanche, K. Durrheim, \& D. Painter (Eds.), Research in practice (2nd ed., pp. 321-344). Cape Town, South Africa: University of Cape Town Press.

Timm, V. M. (2007). Behaviour problems in primary schools in Mamelodi: An ecological construction. (Unpublished master's dissertation). University of Pretoria, Pretoria, South Africa.

Townsend, L., Fisher, A. J., Chikobvu, P., Lombard, C., \& King, G. (2008). The relationship between bullying behaviours and high school dropout in Cape Town South Africa. South African Journal of Psychology, 38, 21-32.

Wolhuter, C. C., \& Steyn, S. C. (2003). Learner discipline at school: A comparative educational perspective. Bulletin for Christian Fellowship, 68, 521-538. 